\title{
Business Process Reengineering Pada Kejaksaan Negeri Batu
}

\author{
Damar Arya P.M ${ }^{*}$, Wildan Suharso ${ }^{2}$, Maskur ${ }^{3}$ \\ 1,2,3 Teknik Informatika/Universitas Muhammadiyah Malang \\ damararya707@gmail.com”, wsuharso@umm.ac.id², maskur@umm.ac.id ${ }^{3}$
}

\begin{abstract}
Abstrak
Setiap Instansi yang menyediakan sebuah pelayanan kepada masyarakat menginginkan sebuah layanan yang berkualitas. Meningkatkan sebuah kualitas pada pelayanan perlu memahami kekurangan selama ini. Kejaksaan Negeri Batu adalah sebuah instansi di Provinsi Jawa Timur yang pelayanan masih berjalan secara manual. Hal ini menimbulkan permasalahan dari segi pelayanan, kecepatan dan biaya kepada masyarakat. Berdasarkan masalah ini perlu dilakukan perubahan proses bisnis pada Kejaksasaan Negeri Batu dengan penerapan BPR (Business Process Reengineering). Business Process Reengineering adalah konsep untuk mengubah ulang proses bisnis yang memiliki kelemahan pada proses. Tujuanya untuk memperbaiki sebuah kinerja proses agar lebih efisien. Penelitian dimulai dengan mengumpulkan beberapa referensi yang berkaitan dengan Business Process Reengineering. Metode pengumpulan data dilakukan dengan cara observasi ke studi kasus, wawancara dengan pihak Kejaksaan Negeri Batu dan studi literatur sejenis. Memahami suatu proses bisnis digunakan peta proses standar ASME (American Society of Mechanical Engineers). Berdasarkan peta proses standar ASME dapat dihitung kinerja proses bisnis dengan menghitung efisiensi throughput. Langkah peningkatan dan penyempurnaan desain ulang proses dilakukan agar proses bisnis lebih efektif. Hasil akhir penelitian adalah sebuah rancangan ulang model bisnis proses rekomendasi yang meningkatkan efisiensi throughput dari 50,36\% pada proses sebelumnya menjadi $85,77 \%$ dan menghasilkan sebuah aplikasi sebagai pendukung rancangan ulang model bisnis proses rekomendasi.
\end{abstract}

Kata Kunci: BPR, efisiensi throughput, ASME, TI, Kejaksaan Negeri Batu

\begin{abstract}
Every agency that provides a service to the public wants a quality service. Improving a quality of service needs to understand the shortcomings. State Attorney Batu is an agency in East Java Province that service is still running manually. This creates problems in terms of service, speed and cost to the community. Based on this problem, it is necessary to change the business process at State of the Earth Stone with the application of BPR (Business Process Reengineering). Business Process Reengineering is a concept to re-alter a business process that has a weakness in the process. The goal is to improve a process performance to be more efficient. Research begins by collecting some references related to Business Process Reengineering. Data collection method was done by observation to case study, interview with State Prosecutor of Batu and study of similar literature. Understanding a business process is used ASME standard process maps (American Society of Mechanical Engineers). Based on ASME standard process maps can be calculated business process performance by calculating throughput efficiency. Steps to improve and refine the process redesign are done to make business processes more effective. The final results are a redesign of business models that improve the efficiency of the process on the throughput of $50.36 \%$ in the previous process becomes $85.77 \%$ and produce an application to support the redesign of the business model of the recommendation process.
\end{abstract}

Keywords: BPR, Throughput Efficiency, ASME, TI, Batu District Attorney

\section{Pendahuluan}

Reengineering atau rekayasa ulang sistem adalah proses mengubah sebuah sistem yang nantinya mampu menambah fungsionalitas baik performa dan keandalanya dan mampu meningkatkan maintainbilitiy. Suatu sistem perlu dilakukan reenginering karena sistem yang lama tidak cocok dengan kondisi lingkungan bisnis yang terus berubah, munculnya kebutuhan baru ketika sistem yang lama digunakan [1]. Istilah Reengineering pertama kali muncul dibidang 
teknologi informasi (TI) pada tahun 1990-an lalu berkembang ke proses perubahan yang lebih luas. Teknologi informasi (TI) merupakan teknologi komputer yang dipadukan dengan teknologi telekomunikasi sehingga teknologi informasi ( $\mathrm{TI}$ ) adalah teknologi yang berhubungan dengan sebuah pengolahan data dan menjadi sebuah informasi. Teknologi informasi memegang peranan penting dalam Business Process Reenginering dikarenakan, ( $\mathrm{TI}$ ) mampu mengubah aturan lama yang menghalangi orang dalam melakukan pekerjaanya [2].

Business Process Reengineering adalah bagian dari reengineering. Business Process Reengineering merupakan sebuah konsep untuk mengubah ulang bisnis proses yang mempunyai titik kelemahan pada prosesnya. tujuanya untuk memperbaiki sebuah kinerja organisasi agar lebih efisien dan kompetitif. Business Process Reengineering bisa diaplikasikan untuk memperbaiki kinerja sebuah usaha, instansi, organisasi dan perusahaan [3]. Salah satu hasil dari Business Process Reengineering adalah mendapatkan sebuah peningkatan yang signifikan dari segi biaya, kecepatan, dan pelayanan [4]. Business Process Reengineering mempunyai hal yang mendasar yaitu pemilik perusahaan atau manajemen harus memiliki dan mempunyai strategi yang efisien dan keberanian untuk meningkatkan kinerja perusahaan dari segala aspek yang nantinya akan menjadi penentu berkembangnya sebuah perusahaan atau manajemen [5]. Beberapa penelitian juga telah menunjukan dengan menggunakan konsep Business Process Reengineering memberikan perubahan yang signifikan. mampu meningkatkan kinerja organisasi. Kisah keberhasilan implementasi Business Process Reengeneering di sebuah organisasi di Singapura. Setelah adanya implementasi. Waktu tunggu dikonter keuangan burkurang hingga $96 \%$, waktu yang diproses berkurang menjadi $44-70 \%$ dan dalam administrasi, waktu untuk mencari file berkurang hingga 54\% [6].

Kejaksaan Negeri Batu merupakan salah satu instansi Kejaksaan Negeri yang terletak di Provinsi Jawa Timur Indonesia. Struktur organisasinya terdiri dari pimpinan dan beberapa bagian. bagian-bagian itu diantaranya bagian Kasubag Pembinaan, bagian Kasi Intelejen, bagian Kasi Pidum, bagian Kasi Pidsus, bagian Kasi Datum dan Kasubag Pembinaan membinai Kaur Kepegawaian, Kaur Keuangan, Kaur Perlengkapan serta Kaur TU dan perpustakaan. Kondisi saat ini pada Kejaksaan Negeri Batu dari segi legasi sistem. Ketika dilakukan analisa pencarian data informasi melalui wawancara tanggal 7 agustus 2017 dengan Pegawai Kaur TU Kejaksaan Negeri Batu. Legasi sistem yang saat ini berlangsung sudah berjalan selama 16 tahun. Aplikasi yang ada atau aplikasi untuk membantu kinerja hanya berupa aplikasi Office seperti Word, Power Point dan Excel. Proses bisnis yang ada di Kejaksaan Negeri Batu ketika dianalisa banyak membutuhkan waktu dan ada beberapa proses yang mengeluarkan biaya serta pemakaian kertas yang berlebihan sehingga kondisi ini membuat kesulitan bagi pegawai.

Hipotesis saat ini beberapa proses seperti proses pengaduan yang dimana menggunakan metode konvensional dimana masyarakat untuk mengajukan pengaduan harus datang ke kejaksaan dan menunggu untuk bertatap muka dengan pegawai sehingga dari segi pelayanan sangat kurang dapat di Reengineering dengan menggunakan metode Business Process Reenginering. pada dasarnya pihak Kejakasaan menginginkan sebuah perubahan untuk meningkatkan kinerja pegawainya dan mempermudah pelayanan untuk masyarakat. Nantinya ketika dianalisa lebih mendalam hasil dari penelitian ini adalah sebuah sistem aplikasi untuk membantu kinerja Kejaksaan Negeri Batu. sehingga diharapkan dengan menerapkan Business Process Reenginering mampu menyelesaikan masalah di Kejaksaan Negeri Batu.

\section{Metode Penelitian}

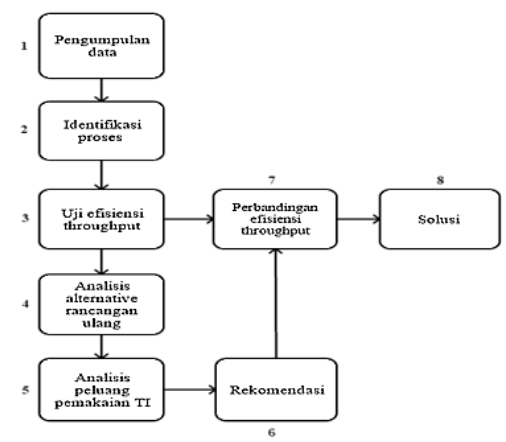

Gambar 1. BPR (Business Process Reengineering)

REPOSITOR, Vol. 1, No. 2, Desember 2019: 159-170 
Metodologi pada penelitian ini digunakan metode Business Process Reengineering yang didalamnya terdapat metode pengumpulan data dan keterangan-keterangan yang diperlukan dan tahap yang harus dilakukan penelitian sebelumnya [7][8] ditunjukkan pada Gambar 1.

Gambar 1 menjelaskan tahap yang ada pada Business Process Reengineering mulai dari tahap awal tahap pengumpulan data sampai pada tahap akhir tahap solusi

\section{Hasil Penelitian Dan Pembahasan}

Hasil dan pembahasan berisi tentang setiap tahap yang dilakukan dengan menggunakan metode BPR (Business Process Reengineering). Observasi adalah metode pengumpulan data berupa pengamatan ketempat yang bersangkutan. Pada observasi peneliti melakukan pengamatan ke Kejaksaan Negeri Batu untuk mengamati proses yang sedang berjalan dan mengetahui peran perbidang dalam menjalankan proses-proses tersebut. Wawancara dilakukan dua kali di Kejaksaan Negeri Batu dengan Pegawai Kaur TU Kejaksaan Negeri Batu tanggal 7 Agustus 2017 dan dilakukan wawancara lagi pada setiap Bidang yaitu Bidang Intelijen, Bidang Pidum dan Bidang Perpustakaan tanggal 23 Oktober 2017. Studi literatur dilakukan dengan membaca dan mempelajari jurnal atau buku dan penelitian yang serupa dengan Business Process Reengineering. Business Process Reengineering pada jurnal Metode BPR (Business Process Reengineering) dalam membangun aplikasi curriculum vitae dosen berdasarkan template sertifikasi pendidik [9]. Melakukan Studi literatur tentang merancang kerangka konseptual penelitian dan diagram alir penelitian pada jurnal Konsep Business Process Reengineering guna pembenahan sistem dan kinerja bisnis perusahaan manufaktur [10].

\subsection{Metode Pengumpulan Data}

Dalam metode pengumpulan data dilakukan pengumpulan data dan pencarian data untuk memenuhi keperluan yang dibutuhkan. Data diperoleh dari observasi tempat studi kasus, wawancara dengan pihak Kejaksaan Negeri Batu dan studi literatur sejenis.

\subsection{Identifikasi Proses}

Pada tahap ini mengindentifikasi dan memahami legacy sistem dan alur proses bisnis yang ada pada Kejakasaan Negeri Batu dan memahami struktur organisasi, bagian-bagian pegawai atau keterlibatan pegawai dalam menjalankan proses bisnis yang sedang berlangsung. Struktur organisasi pada Kejaksaan Negeri Batu ditunjukkan pada Gambar 2.

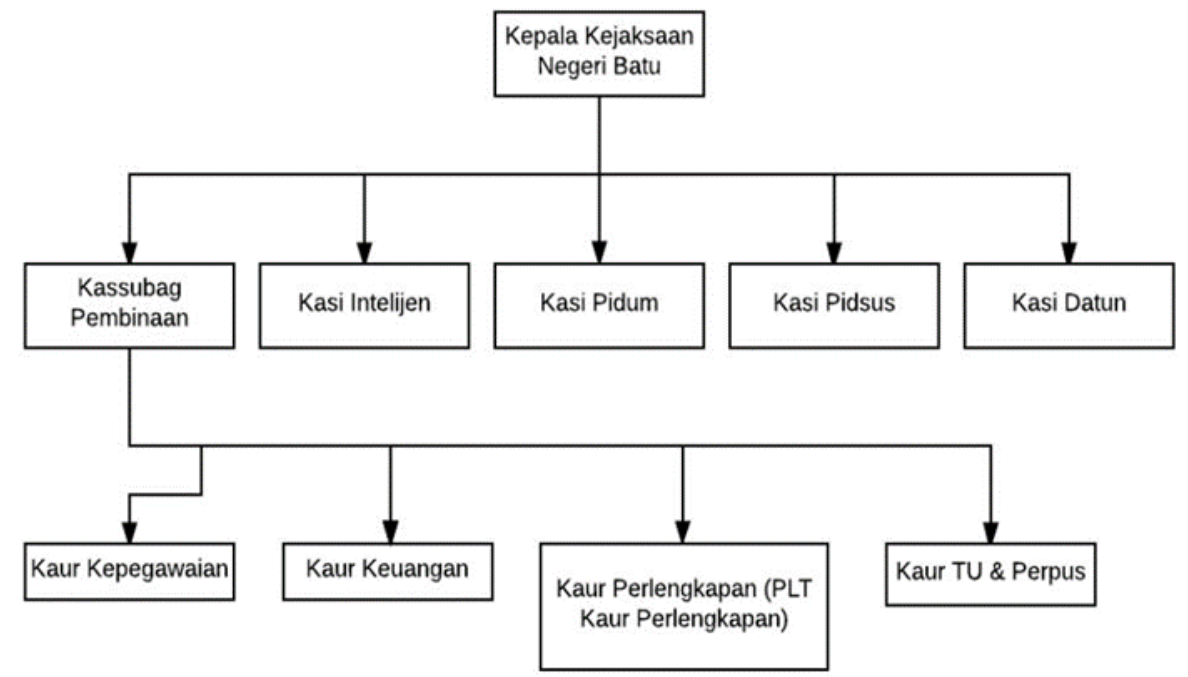

Gambar 2. Struktur Organisasi Kejaksaan Negeri Batu

Gambar 2 menjelaskan tentang struktur organisasi pada Kejaksaan Negeri Batu yang dimana ada bagian Kepala Kejaksaan Negeri Batu, Kassubag Pembinaan, Kasi Intelijen, Kasi Pidum, Kasi Pidsus dan Kasi Datun. Kassubag Pembinaan membinai Kaur Kepegawaian, Kaur Keuangan, Kaur Perlengkapan, Kaur TU \& Perpustakaan. Kejaksaan Negeri Batu memiliki proses bisnis dalam menjalankan pekerjaan setiap bagian. 
Pengumpulan data yang dilakukan di Kejaksaan Negeri Batu dengan cara observasi dan wawancara dengan pegawai pada Kejaksaan Negeri Batu ditemukan bahwa beberapa proses seperti proses pengaduan diidentifikasi mempunyai titik kelemahan dari segi biaya, pelayanan dan kecepatan. Proses bisnis pengaduan, akan dibentuk ke diagram flowchart sehingga mudah untuk dilihat dan diidentifikasi ditunjukan pada Gambar 3.

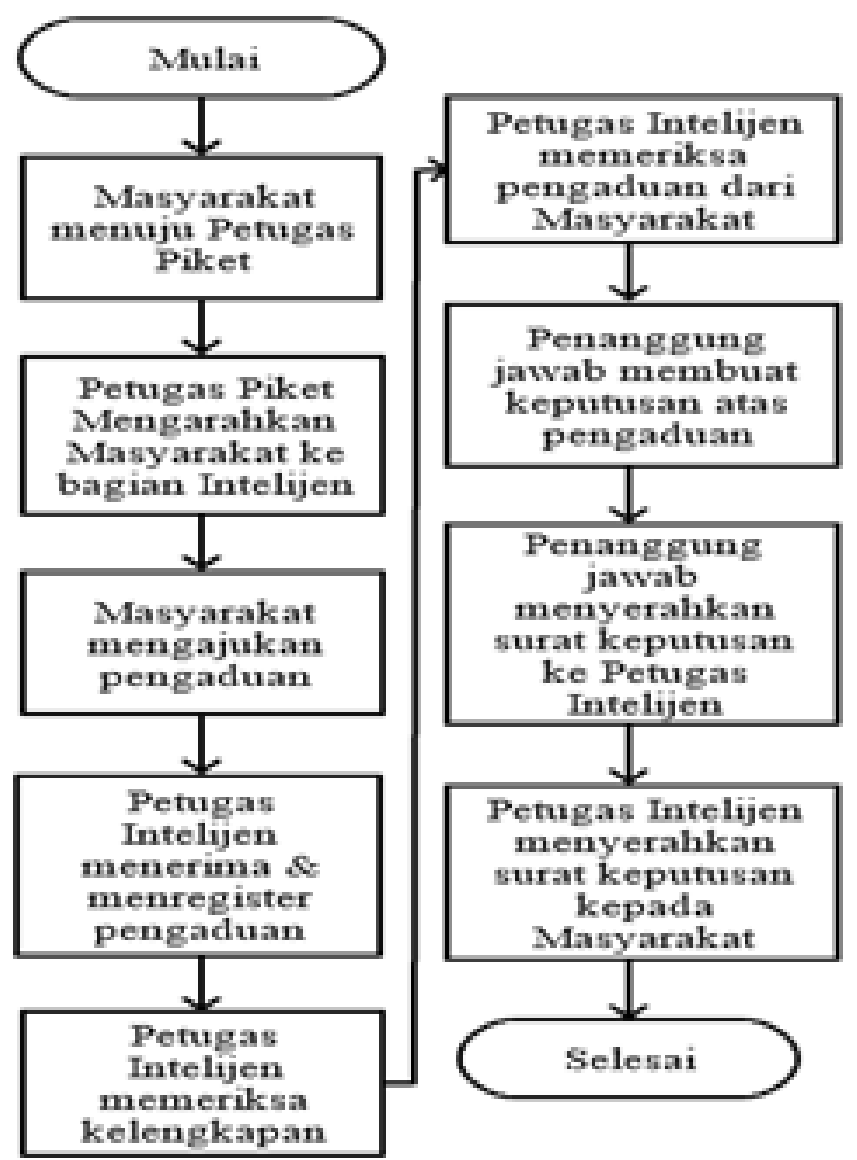

Gambar 3. Proses Bisnis Pengaduan

Gambar 3 menjelaskan tentang proses pengaduan dimana masyarakat untuk melakukan pengaduan harus menuju ke petugas piket yang ada dilobby untuk menjelaskan tujuannya. Petugas piket mengarahkan masyarakat ke bidang Intelijen sampai dengan proses

akhir yaitu petugas Intelijen menyerahkan surat keputusan kepada masyarakat. Pada proses ini terdapat penanggung jawab dimana penanggung jawab ini adalah petugas Intelijen juga yang bagianya sebagai penanggung jawab dalam membuat surat keputusan.

\subsection{Uji Efisiensi Througput}

Pada tahap ini dilakukan pengujian pada proses bisnis pengaduan pada Kejaksaan Negeri Batu. Proses yang mempunyai kelemahan dari segi waktu pelayanan diuji dengan menggunakan uji efisiensi throughput uji waktu pelayanan secara keseluruhan. Dipetakan dengan peta standar ASME (American Society of Mechanical Engineers). Tujuan dilakukan uji efisiensi throughput dan pemetaan standar ASME (American Society of Mechanical Engineers) untuk mengetahui dan mengukur kinerja waktu pelayanan secara keseluruhan masuk dalam berapa persen dan nantinya akan dibandingkan dengan rancangan desain ulang proses bisnis rekomendasi dari segi model dan hasil. Pemetaan standar ASME dan uji efisiensi throughput pada proses pengaduan ditunjukan pada Tabel 1.

Tabel 1 adalah tabel peta standar ASME dari proses pengaduan pada Kejaksaan Negeri Batu dimana pada pemetaan standar ASME ini terdapat tahap proses, simbol proses, $\mathrm{wkt} / \mathrm{mnt}$ proses dan pemilik proses. Satu hari kerja pada Kejaksaan Negeri Batu adalah 8 jam atau jika

REPOSITOR, Vol. 1, No. 2, Desember 2019: 159-170 
dimenit kan adalah 480 menit. Pemilik proses pada tabel standar ASME ini adalah masyarakat, petugas piket dan petugas Intelijen. Selesai dilakukan pemetaan standar ASME selanjutnya dlakukan uji efisiensi throughput. Uji untuk mengukur kinerja waktu pelayanan secara keseluruhan dari hasil pemetaan standar ASME proses pengaduan dengan Persamaan 1.

Tabel 1. Peta Proses Standar ASME Pengaduan

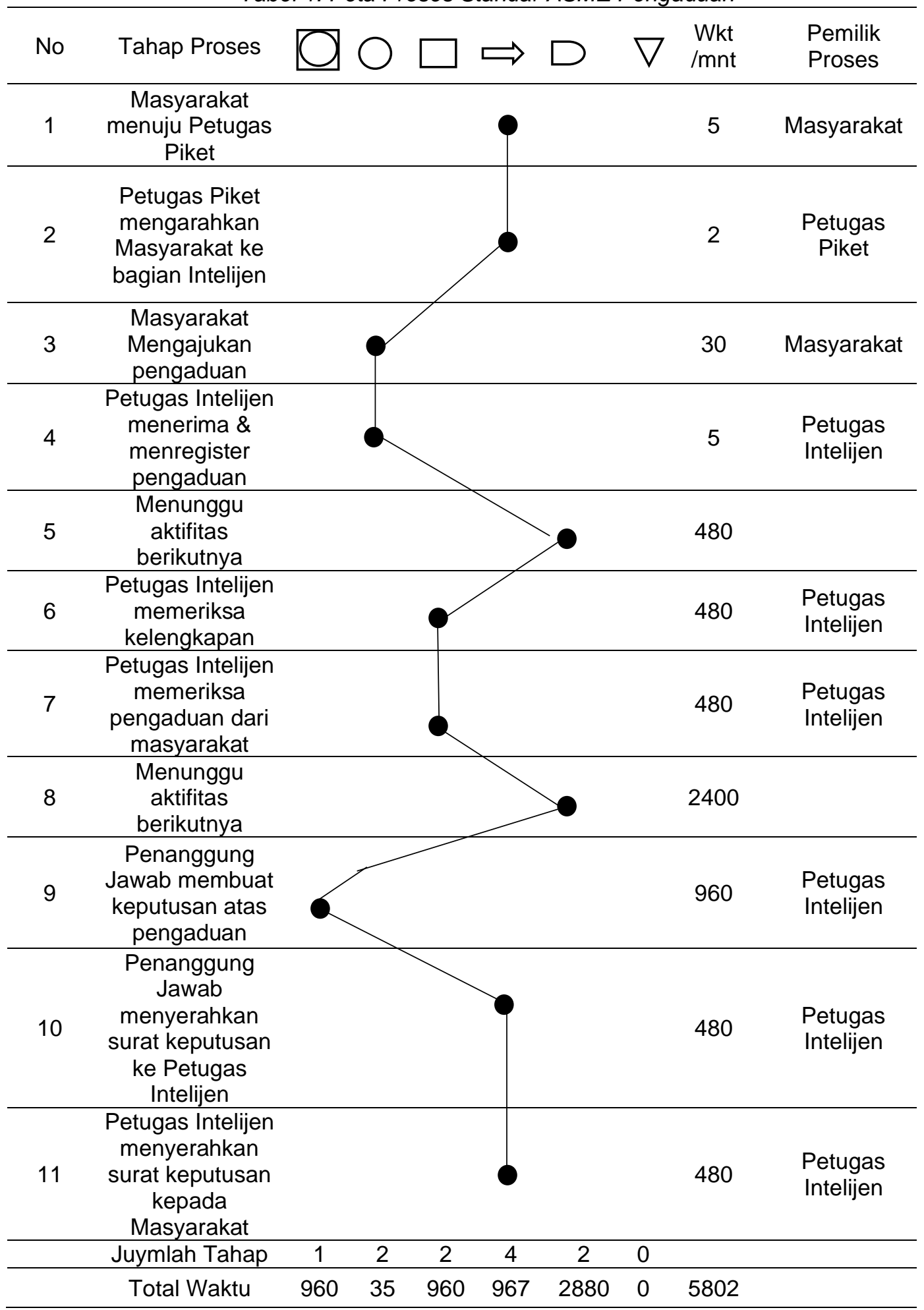




$$
\begin{aligned}
\text { efisiensi throughput } & =\frac{\text { waktu proses bukan tunda }}{\text { total waktu dalam sistem }} \times 100 \% \\
& =\frac{2922}{2922+2880} \times 100 \% \\
& =\frac{2922}{5802} \times 100 \% \\
& =50,36 \%
\end{aligned}
$$

Hasil dari uji efisiensi throughput dari pemetaan standar ASME pada proses pengaduan. Rumus efisiensi throughput adalah waktu proses bukan tunda dibagi dengan total waktu dalam sistem dikali dengan 100\%. Nilai 2922 adalah proses yang tidak mengalami waktu tunda sedangkan nilai 2880 adalah proses yang mengalami waktu tunda dengan simbol delay.

\subsection{Analisis Alternative Rancangan Ulang}

Pada tahap ini dilakukan analisis alternative rancangan ulang dimana pada tahap ini proses

\begin{tabular}{|c|c|c|}
\hline No & Tahap Proses & Langkah Penyempurnaan \\
\hline 1 & Masyarakat menuju Petugas Piket & Eliminasi \\
\hline 2 & $\begin{array}{l}\text { Petugas Piket mengarahkan } \\
\text { Masyarakat ke Bagian Intelijen }\end{array}$ & Eliminasi \\
\hline 3 & $\begin{array}{l}\text { Masyarakat Mengajukan } \\
\text { pengaduan }\end{array}$ & $\begin{array}{l}\text { Automate mengajukan } \\
\text { pengaduan secara online }\end{array}$ \\
\hline 4 & $\begin{array}{l}\text { Petugas Intelijen menerima \& } \\
\text { menregister pengaduan }\end{array}$ & \\
\hline 5 & Menunggu aktifitas berikutnya & \\
\hline 6 & $\begin{array}{c}\text { Petugas Intelijen memeriksa } \\
\text { kelengkapan }\end{array}$ & \\
\hline 7 & $\begin{array}{l}\text { Petugas Intelijen memeriksa } \\
\text { pengaduan dari masyarakat }\end{array}$ & \\
\hline 8 & Menunggu aktifitas berikutnya & Eleminasi \\
\hline 9 & $\begin{array}{l}\text { Penanggung Jawab membuat } \\
\text { keputusan atas pengaduan }\end{array}$ & \\
\hline 10 & $\begin{array}{c}\text { Penanggung Jawab menyerahkan } \\
\text { surat keputusan ke Petugas } \\
\text { Intelijen }\end{array}$ & \\
\hline 11 & $\begin{array}{c}\text { Petugas Intelijen menyerahkan } \\
\text { surat keputusan kepada } \\
\text { Masyarakat }\end{array}$ & $\begin{array}{c}\text { Automate Petugas } \\
\text { Intelijen menyerahkan } \\
\text { surat keputusan ke } \\
\text { Masyarakat secara online }\end{array}$ \\
\hline
\end{tabular}
bisa dirancang secara berbeda dengan cara melakukan penyempurnaan desain ditunjukan pada Tabel 2.

Tabel 2. Penyempurnaan Proses Bisnis Pengaduan

Tabel 2 adalah tabel penyempurnaan proses bisnis pengaduan dimana pada tahap ini melakukan analisis alternative rancangan ulang. Analisis alternative rancangan ulang dilakukan dengan penghilangan beberapa proses yang tidak memberikan nilai tambah. Melakukan otomatisasi dimana aktivitas yang dilakukan manual diganti dilakukan dengan aktivitas bantuan komputer.

\subsection{Analisis Peluang Pemakaian (TI) Teknologi Informasi}

Pada tahap ini dilakukan analisis peluang pemakaian Teknologi Informasi pada Kejaksaan Negeri Batu dimana mampu mendukung rancangan ulang desain proses bisnis. menemukan komponen teknologi informasi yang ada pada Kejaksaan Negeri Batu. Menganalisis peluang pemakaian ( $\mathrm{TI}$ ) teknologi informasi IT levers. Hasil wawancara tanggal 23 oktober dengan bidang perlengkapan untuk mencari data komponen teknologi informasi pada Kejaksaan Negeri Batu dan dari hasil ini mendapatkan data yang dicari.

REPOSITOR, Vol. 1, No. 2, Desember 2019: 159-170 


\subsection{Rekomendasi}

Pada tahap ini dilakukan perancangan ulang proses bisnis pada Kejaksaan Negeri Batu sehingga menjadi rancangan desain ulang proses bisnis rekomendasi. Selesai dirancang ulang akan dilakukan pengujian uji efisiensi throughput pada proses rekomendasi. Rancangan proses rekomendasi ditunjukan pada Gambar 4.

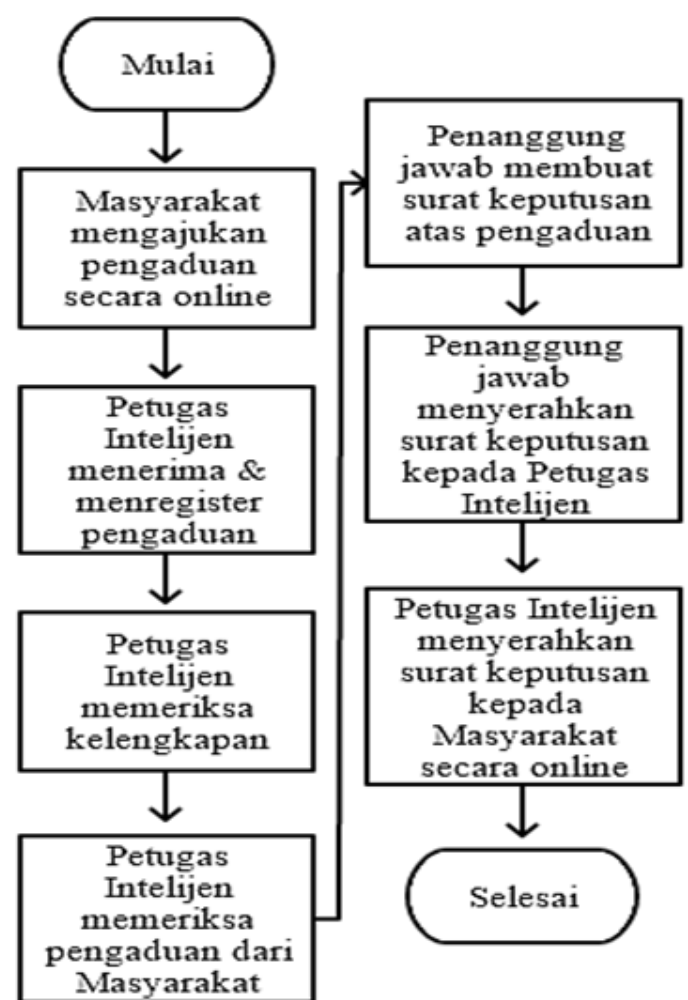

Gambar 4. Proses Bisnis Pengaduan Rekomendasi

Gambar 4 adalah proses bisnis pengaduan rekomendasi dimana pada proses ini sudah dilakukan analisis alternative rancangan ulang dengan menghilangkan proses yang tidak memberikan nilai tambah dan mengotomatisasi proses. Untuk analisis peluang pemakaian teknologi informasi disesuaikan dengan IT levers. Proses rekomendasi yang sudah dirancang selanjutnya dilakukan tabel pemetaan standar ASME dan pengujian efisiensi throughput pengujian waktu pelayanan secara keseluruhan. Peta standar ASME ditunjukan pada Tabel 3.

Tabel 3 adalah tabel peta proses standar ASME pengaduan rekomendasi. Pada tabel ini masyarakat dapat mengajukan pengaduan secara online. Petugas Intelijen juga dapat menyerahkan surat keputusan kepada masyarakat secara online. Pada tabel peta standar ASME pengaduan ini pemilik proses petugas piket dihilangkan masyarakat tidak perlu menuju petugas piket. Masyarakat bisa langsung mengajukan pengaduan secara online dimanapun. Setelah dilakukan pemetaan standar ASME pada proses pengaduan rekomendasi. Selanjutnya dilakukan uji efisiensi throughput.

Hasil uji efisiensi throughput pada Persamaan 2 rancangan desain ulang proses pengaduan rekomendasi memberikan presentase yang tinggi yaitu $85,77 \%$ dan sisanya adalah $14.23 \%$ waktu pealayanan dalam sistem tidak berjalan.

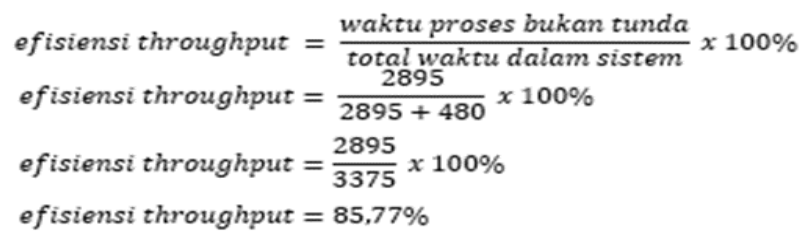


Tabel 3. Peta Proses Standar ASME Pengaduan Rekomendasi

\begin{tabular}{|c|c|c|c|c|c|c|c|c|c|}
\hline No & Tahap Proses & $\Delta$ & $U$ & 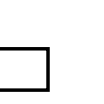 & $\Longrightarrow$ & $\square$ & $\nabla$ & $\begin{array}{l}\text { Wkt } \\
/ \mathrm{mnt}\end{array}$ & $\begin{array}{l}\text { Pemilik } \\
\text { Proses }\end{array}$ \\
\hline 1 & $\begin{array}{c}\text { Masyarakat } \\
\text { mengajukan } \\
\text { pengaduan } \\
\text { secara online }\end{array}$ & & & & & & & 10 & Masyarakat \\
\hline 2 & $\begin{array}{c}\text { Petugas } \\
\text { Intelijen } \\
\text { menerima \& } \\
\text { menregister } \\
\text { pengaduan }\end{array}$ & & & & & & & 5 & $\begin{array}{l}\text { Petugas } \\
\text { Intelijen }\end{array}$ \\
\hline 3 & $\begin{array}{l}\text { Menunggu } \\
\text { aktifitas } \\
\text { berikutnya }\end{array}$ & & & & & & & 480 & \\
\hline 4 & $\begin{array}{c}\text { Petugas } \\
\text { Intelijen } \\
\text { memeriksa } \\
\text { kelengkapan }\end{array}$ & & & & & & & 480 & $\begin{array}{l}\text { Petugas } \\
\text { Intelijen }\end{array}$ \\
\hline 5 & $\begin{array}{c}\text { Petugas } \\
\text { Intelijen } \\
\text { memeriksan } \\
\text { pengaduan } \\
\quad \text { dari } \\
\text { masyarakat } \\
\end{array}$ & & & & & & & 480 & $\begin{array}{l}\text { Petugas } \\
\text { Intelijen }\end{array}$ \\
\hline 6 & $\begin{array}{l}\text { Penanggung } \\
\text { Jawab } \\
\text { membuat surat } \\
\text { keputusan } \\
\text { atas } \\
\text { pengaduan }\end{array}$ & & & & & & & 960 & $\begin{array}{c}\text { Penanggung } \\
\text { Jawab }\end{array}$ \\
\hline 7 & $\begin{array}{l}\text { Penanggung } \\
\text { Jawab } \\
\text { menyerahkan } \\
\text { surat } \\
\text { keputusan } \\
\text { kepada } \\
\text { Petugas } \\
\text { Intelijen } \\
\end{array}$ & & & & & & & 480 & $\begin{array}{c}\text { Penanggung } \\
\text { Jawab }\end{array}$ \\
\hline 8 & $\begin{array}{c}\text { Petugas } \\
\text { Intelijen } \\
\text { menyerahkan } \\
\text { surat } \\
\text { keputusan } \\
\text { kepada } \\
\text { Masyarakat } \\
\text { secara online }\end{array}$ & & & & 0 & & & 480 & $\begin{array}{l}\text { Petugas } \\
\text { Intelijen }\end{array}$ \\
\hline & Jumlah Tahap & 1 & 2 & 2 & 2 & 1 & 0 & & \\
\hline & Total Waktu & 960 & 15 & 960 & 960 & 480 & 0 & 3375 & \\
\hline
\end{tabular}

\subsection{Perbandingan Efisiensi Throughput}

Pada tahap ini membandingkan waktu pelayanan secara keseluruhan pada proses rekomendasi dan proses awal. Selain membandingkan waktu pelayanan pada tahap ini juga membandingkan alur proses dan membandingkan segi kecepatan, biaya dan pelayanan. Tabel pembanding antara rancangan desain ulang proses bisnis rekomendasi dan rancangan proses awal pada Kejaksaan Negeri Batu ditunjukan pada Tabel 4. 


\begin{tabular}{ccccccc}
\hline No & $\begin{array}{c}\text { Proses } \\
\text { Bisnis }\end{array}$ & $\begin{array}{c}\text { Efisiensi } \\
\text { throughput } \\
\text { Awal }\end{array}$ & $\begin{array}{c}\text { Efisiensi } \\
\text { Throughput } \\
\text { Rekomendasi }\end{array}$ & $\begin{array}{c}\text { Kecepatan } \\
\text { Proses } \\
\text { Awal }\end{array}$ & $\begin{array}{c}\text { Kecepatan } \\
\text { Proses } \\
\text { Rekomendasi }\end{array}$ & Biaya \\
\hline 1 & $\begin{array}{c}\text { Proses } \\
\text { Pengaduan }\end{array}$ & $50,36 \%$ & $85,77 \%$ & $5802 \mathrm{mnt}$ & $3375 \mathrm{mnt}$ & - \\
\hline
\end{tabular}

Tabel 4 adalah tabel pembanding proses pengaduan dimana pada tabel ini membandingkan proses pengaduan awal dan proses pengaduan rekomendasi. Efisiensi throughput pada proses pengaduan awal Kejaksaan Negeri Batu menghasilkan 50,36\% dengan kecepatan $5802 \mathrm{mnt}$ dan pada rancangan desain ulang proses pengaduan rekomendasi efisiensi throughput menghasilkan 85,77\% dengan kecepatan 3375 mnt.

\subsection{Solusi}

Tahap solusi dimana pada tahap ini menghasilkan sebuah aplikasi yang dapat membantu rancangan desain ulang proses bisnis pengaduan rekomendasi pada Kejaksaan Negeri Batu agar maksimal dan tujuan Business Process Reenginering dapat tercapai. Perlu adanya aplikasi yang sesuai dengan analisis alternative rancangan ulang yang sudah dilakukan dan analisis peluang pemakaian teknologi informasi. Aplikasi pendukung rancangan desain ulang proses bisnis pengaduan rekomendasi ditunjukan pada Gambar 6.

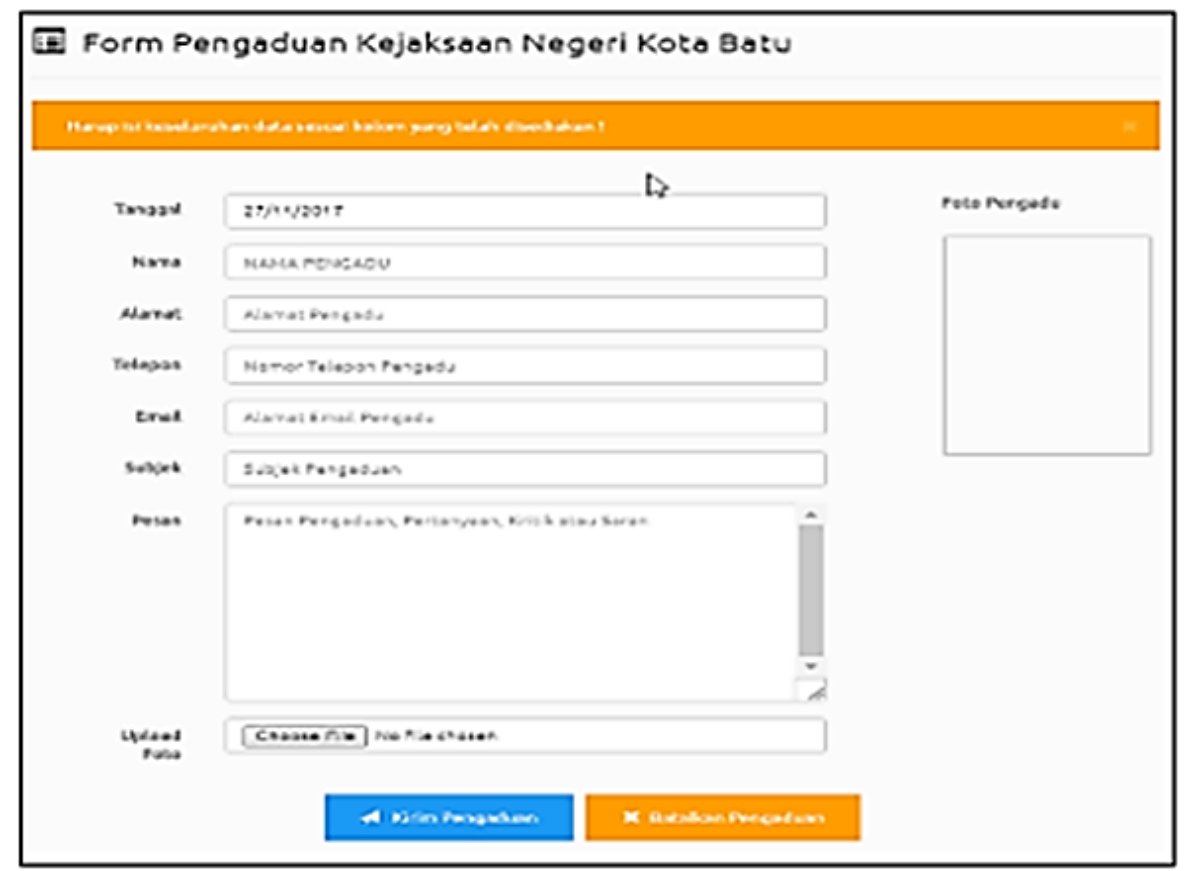

Gambar 6. Aplikasi Pengaduan

Gambar 6 adalah aplikasi pengaduan rekomendasi dimana pada aplikasi ini berdasarkan analisis awal yaitu analisis alternative rancangan ulang dan analisis peluang pemakaian teknologi informasi. Aplikasi akan memudahkan proses bisnis pengaduan rekomendasi menyesuaikan dengan analisis awal dimana masyarakat dapat melakukan pengaduan secara online. Masyarakat mengisi form pengaduan dan mengisi identitas diri seperti tanggal, nama, alamat, telepon, email, subjek, pesan dan upload foto pengaduan dan mengirim pengaduan. Pengaduan yang sudah dikirim akan masuk kedalam data pengaduan dan petugas intelijen akan menerima pesan yang ditunjukan pada Gambar 7 .

Gambar 7 adalah data pengaduan, pada saat masyarakat mengirim pengaduan maka akan masuk ke dalam data pengaduan dan petugas Intelijen akan membaca pengaduan dan menanggapi pengaduan masyarakat. Aplikasi digunakan untuk membantu rancangan ulang proses bisnis pengaduan rekomendasi sesuai dengan tahapan dan analisis Business Process Reengineering yang sudah dilakukan. 


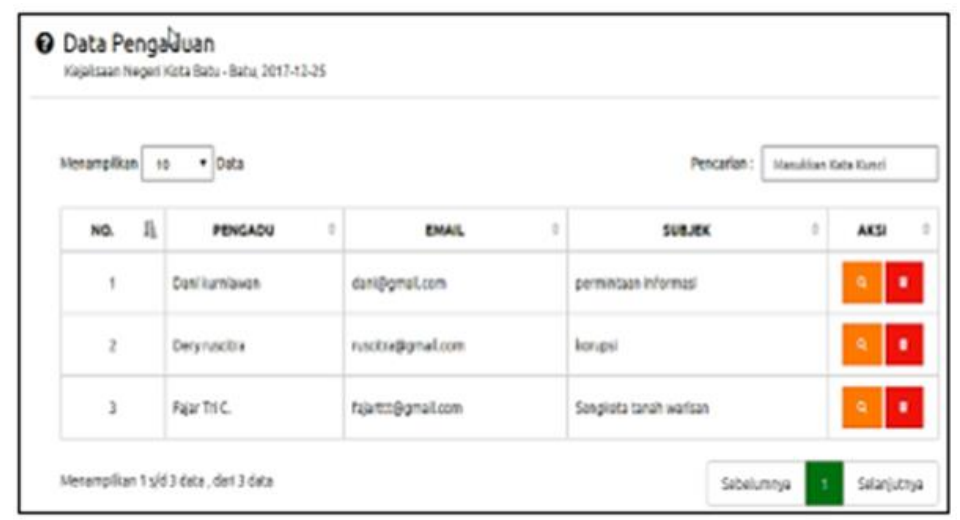

Gambar 7. Data Pengaduan

\section{Kesimpulan Dan Saran}

Dari hasil penelitian yang dilakukan berikut ini adalah kesimpulan dan saran dari penelitian:

\subsection{Kesimpulan}

1. Business Process Reenginering mampu mengubah proses yang lama ke proses rekomendasi. Melakukan pengumpulan data sehingga proses awal ditemukan. Dilakukan penyempurnaan desain proses eliminasi penghilangan proses yang tidak memberikan nilai tambah dan melakukan automate dimana proses yang manual diubah menggunakan aktivitas bantuan komputer. Analisis peluang pemakaian teknologi informasi pun dilakukan sehingga dari semua tahap yang dilakukan mampu mengubah proses lama ke proses rekomendasi.

2. Business Process Reenginering mampu mendapatkan perbedaan antara proses lama dan proses rekomendasi dari segi pelayanan, kecepatan dan biaya. pada proses pengaduan dilakukan uji efisiensi throughput dengan hasil pada proses pengaduan lama 50,36\% dan pada proses pengaduan rekomendasi $85,77 \%$. Proses pengaduan rekomendasi lebih unggul karena waktu pelayanan $85,77 \%$ berjalan dengan baik dengan kecepatan 3375 menit.

3. Business Process Reenginering mampu membuat rancangan model bisnis rekomendasi dimana sudah dilakukan analisis alternative rancangan ulang dan analisis peluang pemakaian teknologi informasi mulai dari mencari komponen teknologi informasi yang ada pada Kejaksaan Negeri Batu dan identifikasi IT levers. Menghasilkan aplikasi yang memudahkan bisnis proses rekomendasi, aplikasi sesuai dengan analisis awal yaitu analisis alternative rancangan ulang dan analisis peluang pemakaian teknologi informasi. Aplikasi sebagai pendukung proses bisnis rekomendasi agar proses rekomendasi dapat berjalan dengan maksimal.

\subsection{Saran}

Dari hasil penelitian yang dilakukan masih bisa dikembangkan beberapa proses yang ada pada Kejaksaan Negeri Batu seperti penyimpanan berkas dan perpustakaan dan disposisi surat diidentifikasi memiliki kelemahan dan pada proses bisnis ini dapat dterapkan Business Process Reengineering untuk merancang ulang proses bisnis. Pada bisnis proses penyimpanan berkas, perpustakaan dan disposisi surat juga diidentifikasi dapat dilakukan pembuatan aplikasi dengan analisis metode SDLC.

\section{Referensi}

[1] R. P. Suropaty and E. D. Wahyuni, "Sistem Informasi Manajemen Layanan SMS Center Universitas Muhammadiyah Malang," vol. 1, no. 2, pp. 91-100, 2016.

[2] R. D. Richardus Eko indrajit, Business Process Reengineering. 2002.

[3] D. D. Wimpertiwi, "Konsep Business Process Reengineering Untuk Memperbaiki Kinerja Bisnis Menjadi Lebih Baik: Studi Kasus Perusahaan Susu Kedelai 'Xyz ,'” Binus Bus. Rev., vol. 5, no. 2, pp. 658-668, 2014.

[4] M. Attaran, "Exploring the relationship between information technology and business process reengineering," Inf. Manag., vol. 41, no. 5, pp. 585-596, 2004.

[5] M. S. Rejeki and A. Tarmuji, "Membangun Aplikasi Autogenerate Script Ke Flowchart Untuk Mendukung Business Process Reengineering," Peranc. Sist. Inf., vol. Volume 1, pp. 448456, 2013.

REPOSITOR, Vol. 1, No. 2, Desember 2019: 159-170 
[6] A. D. Yulianto, "Perancangan Sistem Informasi Kemetrologian dalam Pendekatan Business Process Reengineering untuk Pelayanan Tera," Jnteti, vol. 3, no. 3, pp. 174-178, 2014.

[7] N. L. Wisayani, Kertahadi, and Riyadi, "Analisis Business Process Reengineering Untuk Mengevaluasi, Merekayasa Ulang, Dan Memperbaiki Monitoring Kontrak Pada Pt Pln (Persero) Dist. Jatim Area Malang.," J. Adm. Bisnis, vol. Vol.8 No.I, no. 1, pp. 1-10, 2014.

[8] H. Wasiati, "Rekayasa Ulang Layanan Praktek Kerja Lapangan Mahasiswa Menggunakan Business Process Reengineering Di Stmik Akakom Yogyakarta," J. Teknol. Inf. Respati, vol. 10, no. 28, 2015.

[9] H. Suroko, "Metode BPR (Business Process Reengineering) Dalam Membangun Aplkasi Curriculum Vitae Dosen Berdasarkan Template Sertifikasi Pendidik," Unirversitas Islam Negeri Syarif Hidayatullah Jakarta, 2011.

[10] T. I. Dani Eko Wiyono1, Farham HM Saleh2, "Konsep business process engineering guna pembenahan sistem dan kinerja bisnis perusahaan manufaktur," pp. 165-172, 2017. 
REPOSITOR, Vol. 1, No. 2, Desember 2019: 159-170 